\title{
Estimation of large-scale sea-ice motion from SSM/I 85.5 GHz imagery
}

\author{
Tom A. Agnew, ${ }^{1}$ Hao Le, ${ }^{1}$ Tom Hirose ${ }^{2}$ \\ ${ }^{1}$ Climate and Atmospheric Research Directorate, Atmospheric Environment Service, Downsview, Ontario M3H 5 T4, Canada \\ ${ }^{2}$ NOETIX Research Inc., 978 Merivale Road, Ottawa, Ontario K126A4, Canada
}

\begin{abstract}
This paper describes the application of an automated cross-correlation technique to pairs of $85.5 \mathrm{GHz}$ Special Sensor Microwave Imager (SSM/I) images to obtain ice motion over the entire Arctic Basin for a contiguous two month period between December 1993 and January 1994. Although the surface ice information in the imagery is coarse and noisy, the area cross-correlation method is quite successful in picking up icemotion information. The accuracy of $85.5 \mathrm{GHz}$ SSM/I derived ice motions is evaluated by comparing results with Arctic buoy drift. Over 390 comparisons with buoy-drift estimates of ice displacement were made with an overall correlation of 0.75 and an average vector magnitude error in ice velocity of $3.5 \mathrm{~km} \mathrm{~d}^{-1}$. The main difficulty with the automated technique is the tendency to overestimate ice displacement compared to buoy data by about $14 \%$. Two detailed examples of ice motion are presented. The first occurred in December 1993, when a major westward shift in the ice pack took place in the Canada Basin and opened up a very large lead off Banks and Prince Patrick Islands. The second example occurred in January 1994, when an intense anticyclone over the Canada Basin produced a strong Beaufort Gyre.
\end{abstract}

\section{INTRODUGTION}

Sea-ice motion is important for understanding climate processes at the sea-ice-atmosphere-ocean interface. Differential ice motion determines the extent of open water within the ice pack, which in turn greatly influences local sensible and latent heat exchange with the atmosphere, the rate of new ice production, brine production within the surface layers of the ocean, and ice ridging and thickness distribution. On longer time-scales, sea-ice motion determines the rate that sea ice is advected out of the Arctic Basin through Fram Strait and into the Canadian Archipelago, and is therefore important in sea-ice budget studies of the Arctic Ocean. This is also important in determining the rate of freshening in the North Atlantic and the intensity of thermohaline circulation in the global ocean (Aagaard and Carmack, 1989).

The $85.5 \mathrm{GHz}$ channels on the Special Sensor Microwave Imager (SSM/I) historically have not been used much for estimating large-scale geophysical properties of sea ice (Steffen and others, 1992) because of the high attenuation of surface microwave emissions due to atmospheric moisture and liquid water. During winter over the Arctic Basin, atmospheric moisture is typically low and atmospheric attenuation is not a serious problem. As a result, the higher pixel resolution of $85.5 \mathrm{GHz}$ imagery, compared to lower frequency channels, can be used to observe the sea-ice surface. It turns out that at pixel resolutions of $12.5 \mathrm{~km}$, large multi-year ice floes and large leads that form over the Arctic Basin can be resolved. Animation of daily SSM/I imagery over periods of several months to several years has been conducted, and the results reveal a dynamic behavior of the seaice pack not previously observed.
To quantify the ice motion seen in the animation, an image-matching technique using maximum cross correlations (MCC) in windowed portions of the two images was used. Several authors developed this method of matching locations between pairs of images: Ninnis and others (1986) first described an automatic technique using maximum cross correlation between sequential images in windowed portions of AVHRR images; Emery and others (1991) applied the technique to estimate ice motion in Fram Strait; Filey and Rothrock (1987) applied a similar technique to image pairs from a Synthetic Aperture Radar (SAR); and Hirose and others (1991) further refined and automated the technique. This paper is the first attempt to apply the technique to coarse resolution $85.5 \mathrm{GHz} \mathrm{SSM} / \mathrm{I}$ imagery to obtain motions over the entire Arctic Basin for a contiguous two month period. The accuracy of $85.5 \mathrm{GHz} \mathrm{SSM} / \mathrm{I}$ derived ice motions is evaluated by comparing results with Arctic drift buoys .

\section{DATA AND METHODOLOGY}

The SSM/I daily average data were obtained on CD-ROM from the National Snow and Ice Data Center (NSIDC, 1994). Each daily image is a mosaic of the 14.1 orbits that occur over the 24 hour period (midnight to midnight GMT). Each orbit has a swath width of $1394 \mathrm{~km}$ resulting in considerable overlap over the Arctic Basin during any 24 hour period. Because the satellite orbit is tilted away from the North Pole axis, there is a circular region $280 \mathrm{~km}$ in radius where no data is collected. The method of binning different orbital brightness temperatures into the $12.5 \mathrm{~km}$ $\mathrm{SSM} / \mathrm{I}$ grid is described in NSIDC (1996).

For comparison with the buoy data, the analysis carried 
out in this paper assumes that each $12.5 \mathrm{~km}$ pixel in the daily mosaic represents the average brightness temperature over this 24 hour period valid at $1200 \mathrm{~h}$ GMT each day. This is generally a sound assumption but for individual cases it creates small timing errors over the Arctic Basin (discussed later). Several years of imagery were animated and a two month period (December 1993 and January 1994) was selected on the basis of strong ice motion in the Arctic Basin and relatively good Arctic buoy coverage. Only horizontal polarized SSM/I imagery was analyzed for ice motion, because it gave a better image contrast than the vertical polarization. A neighbor-substitution algorithm was applied to the original CD-ROM product from NSIDC to correct for occasional missing pixels and poor scan lines. No filtering or removal of cloud was conducted and a land mask was applied to the imagery before ice-motion analysis was carried out on image pairs.

Details of the maximum cross correlation (MCC) technique are described in Ninnis and others (1986) and Emery and others (1991), and therefore will not be described in this paper. The technique, as developed in this application, is contained in a completely automated software package called Tracker developed by Hirose and others (1991). Tracker software has been applied to a variety of satellite imagery, including ERSI SAR, NOAA AVHRR, and RADARSAT SAR. For application to the SSM/I $85.5 \mathrm{GHz}$ imagery, a $7 \times 7$ pixel search window for calculating cross correlations was used, and an estimate of ice displacement between images was performed roughly every 6 pixels $(75 \mathrm{~km})$. Displacement vectors were checked for consistency with surrounding displacement vectors. The estimated ice displacements were then interpolated to the nearest buoy using quintic interpolation of the three closest estimates, and that interpolation then compared to buoy drift.

The buoy data were obtained from the International Arctic Buoy Program established by the Polar Science Center, University of Washington (Thorndike and Colony, 1980). Figure 1 shows the location of most of the buoys used in the study, with the Argos identification number, and buoy drift during the two month study period. Problem buoys,

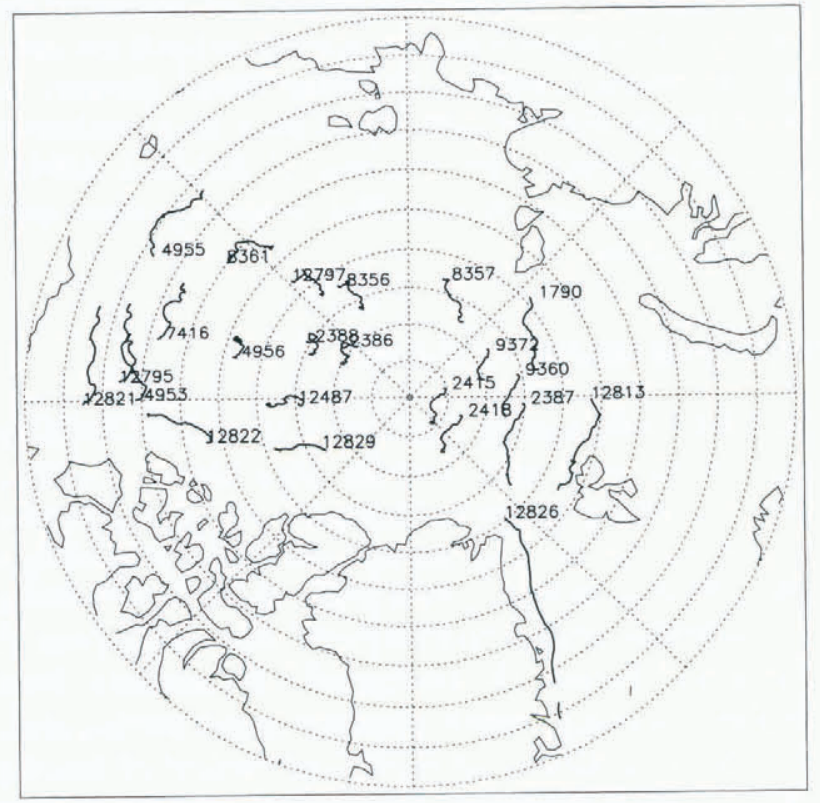

Fig. 1. Observed buoy drift tracks for December 1993 and January 1994. such as those that became caught in the land-fast ice around the cluster of small islands of Franz Josef Land just north of the Barents Sea, were removed from the study. Strong ice motions were estimated in the vicinity of these islands, which were too small to be resolved in the imagery. Buoys which were caught in the land-fast ice off the islands reported no motion for the two month period. The Argos buoy numbers and their latitude/longitude locations are shown in Table 1. All buoys, except number 1108, are near the small islands of Franz Josef Land. Buoy 1108 was probably in the Beaufort Sea area, and only intermittently reported its location (quite often reporting the same location for several weeks at a time). Buoys 3291, 1874, 1795, 1796, 1108 and 1788 were removed from the study. This left $<400$ validation comparisons with the buoy data, and most of these validations were in the western Arctic Basin (the Beaufort, Markarov and Amundsen basins). There were usually 1520 buoys unevenly distributed over the Arctic Basin at any one time. There were 25 image pair runs in the two month period, and most were separated by 3 or 4 days except for run 22, which was separated by 2 days and run 2, which was separated by 5 days (Table 2). No pre-selection of the images was conducted to remove the occasional day when orbital coverage of the Arctic Basin was poor.

Table 1. Location of defective buoys or buoys caught in landfast ice

\begin{tabular}{ccc} 
Argos buoy no. & Latitude & Longitude \\
& & \\
\hline 3291 & $80.06^{\circ} \mathrm{N}$ & $58.98^{\circ} \mathrm{W}$ \\
1874 & $79.28^{\circ} \mathrm{N}$ & $45.63^{\circ} \mathrm{W}$ \\
1795 & $80.39^{\circ} \mathrm{N}$ & $61.57^{\circ} \mathrm{W}$ \\
1796 & $80.48^{\circ} \mathrm{N}$ & $61.70^{\circ} \mathrm{W}$ \\
1108 & $76.81^{\circ} \mathrm{N}$ & $135.28^{\circ} \mathrm{W}$ \\
1788 & $80.57^{\circ} \mathrm{N}$ & $62.37^{\circ} \mathrm{W}$ \\
\end{tabular}

As outlined by Holt and others (1992), there are two main sources of error in measuring ice displacement between images $\mathrm{A}$ and $\mathrm{B}$ : the geographic position error $e_{\mathrm{g}}$ of each image pixel and the tracking error $e_{\mathrm{t}}$ which is the uncertainty in identifying common ice features in the second image. The tracking error applies to a displacement observed between two images. Including errors, the displacement $(s)$ of an ice feature is:

$$
s=x_{\mathrm{B}}+e_{\mathrm{gB}}+e_{\mathrm{t}}-x_{\mathrm{A}}-e_{\mathrm{gA}} .
$$

If $e_{\mathrm{g}}$ is assumed uncorrelated between images, and $e_{\mathrm{g}}$ and $e_{\mathrm{t}}$ are Gaussian with zero mean and std dev. $\sigma_{\mathrm{g}}$ and $\sigma_{\mathrm{t}}$, the error in $s$ will have zero mean and a variance of:

$$
\sigma_{\mathrm{s}}^{2}=2 \sigma_{\mathrm{g}}{ }^{2}+\sigma_{\mathrm{t}}{ }^{2} \text {. }
$$

Geolocation accuracy for the $\mathrm{SSM} / \mathrm{I}$ is $\pm 8 \mathrm{~km}$ (NSIDC, 1996) and, estimating the tracking error to be no better than the pixel resolution, we have $\sigma_{\mathrm{g}}=8 \mathrm{~km}$ and $\sigma_{\mathrm{t}}=12.5 \mathrm{~km}$, which gives a value of $16.8 \mathrm{~km}$ for $\sigma_{\mathrm{s}}$. The error in velocity is $\sigma_{\mathrm{s}}$ divided by the time interval between the images. In this application the time separation between images is typically 4 days, producing a velocity error estimate of $4.2 \mathrm{~km} \mathrm{~d}^{-1}$. The error can be improved by increasing the time interval between images. This however would reduce the time resolution, and increase tracking errors by providing more time for surface features to be modified and/or be distorted. 


\begin{tabular}{|c|c|c|c|c|c|c|c|c|}
\hline Run & Reference image & Match image & Days & Buoy $|\mathbf{B}|$ pixels & Image $|\mathbf{T}|$ pixels & Bias pixels & $|\mathbf{T}-\mathbf{B}|$ pixels & $\mid$ Angle $\mid$ degree \\
\hline 01 & 931201 & 931204 & 3 & 1.32 & 1.41 & 0.09 & 0.64 & 25.7 \\
\hline 02 & 931204 & 931210 & 3 & 2.74 & 2.67 & -0.07 & 0.65 & 12.6 \\
\hline 03 & 931207 & 931211 & 4 & 3.48 & 3.46 & -0.02 & 0.69 & 5.6 \\
\hline 22 & 931210 & 931212 & 2 & 1.39 & 1.94 & 0.55 & 1.18 & 30.5 \\
\hline 04 & 931211 & 931215 & 4 & 2.08 & 2.13 & 0.05 & 0.78 & 20.2 \\
\hline 23 & 931212 & 931215 & 3 & 1.62 & 1.75 & 0.13 & 0.60 & 17.2 \\
\hline 05 & 931215 & 931219 & 4 & 2.43 & 2.42 & -0.01 & 0.73 & 15.6 \\
\hline 06 & 931219 & 931223 & 4 & 3.08 & 3.01 & -0.07 & 0.64 & 10.9 \\
\hline 09 & 931220 & 931224 & 4 & 3.25 & 3.53 & 0.29 & 1.02 & 16.0 \\
\hline 07 & 931223 & 931227 & 4 & 3.02 & 3.18 & 0.16 & 1.39 & 21.1 \\
\hline 10 & 931225 & 931228 & 3 & 1.88 & 2.24 & 0.37 & 0.95 & 21.1 \\
\hline 08 & 931227 & 931231 & 4 & 1.57 & 1.71 & 0.14 & 0.99 & 29.6 \\
\hline 1 & 931231 & 940103 & 3 & 1.81 & 2.23 & 0.42 & 1.29 & 21.3 \\
\hline 2 & 940102 & 940107 & 5 & 2.15 & 2.52 & 0.37 & 1.77 & 49.0 \\
\hline 24 & 940103 & 940107 & 4 & 1.68 & 3.15 & 1.47 & 1.90 & 40.5 \\
\hline 25 & 940107 & 940111 & 4 & 2.11 & 2.49 & 0.38 & 0.82 & 3.8 \\
\hline 3 & 940109 & 940113 & 4 & 2.17 & 2.46 & 0.29 & 1.04 & 23.7 \\
\hline 4 & 940111 & 940114 & 3 & 1.80 & 2.13 & 0.33 & 1.09 & 28.8 \\
\hline 5 & 940113 & 940117 & 4 & 2.10 & 2.12 & 0.02 & 1.13 & 31.7 \\
\hline 26 & 940114 & 940118 & 4 & 1.68 & 2.06 & 0.38 & 0.87 & 35.4 \\
\hline 6 & 940118 & 940122 & 4 & 2.03 & 2.25 & 0.22 & 0.87 & 23.6 \\
\hline 7 & 940122 & 940125 & 3 & 1.46 & 1.49 & 0.02 & 0.38 & 33.2 \\
\hline 27 & 940125 & 940129 & 4 & 0.91 & 1.27 & 0.36 & 0.74 & 37.0 \\
\hline \multirow[t]{2}{*}{8} & 940126 & 940129 & 3 & 1.14 & 1.64 & 0.49 & 0.93 & 33.3 \\
\hline & & Average & 3.6 & 2.02 & 2.29 & 0.28 & 0.96 & 24.3 \\
\hline
\end{tabular}

This error estimate ignores timing errors that arise from the assumption that all pixels in the daily images are valid at $1200 \mathrm{~h}$ GMT. The first timing error effects the time interval between images. Because there are 14.1 orbits $\mathrm{d}^{-1}$, there is a 0.1 of an orbit advance each day. This will effect the mean time interval between daily images by as much as $0.1 /$ $14.1 \times 24 \mathrm{~h}=0.17 \mathrm{~h}$. This is equal to about a $3 \%$ error. Assuming a mean ice velocity of $8 \mathrm{~km} \mathrm{~d}^{-1}$ produces an error estimate of $\pm 0.24 \mathrm{~km} \mathrm{~d}^{-1}$.

The second timing error occurs in the representative GMT time for individual pixels around the Arctic Basin. As one moves around the Arctic Basin, individual pixels will be composed of different orbits the average time of which may be as much as 6 hours away from $1200 \mathrm{~h} \mathrm{GMT.} \mathrm{If} \mathrm{it} \mathrm{is}$ assumed that this is the same for both the reference and the matched image, then the displacements may be valid as much as 6 hours away from $1200 \mathrm{~h}$ GMT. To estimate the random error in velocity that this might produce, a knowledge of the autocorrelation function $(\mu)$ and natural variance $\left(\sigma_{\mathrm{N}}^{2}\right)$ of ice motion is required. Thorndike (1986) estimates $\sigma_{\mathrm{N}}^{2}$ to be $37 \mathrm{~km}^{2} \mathrm{~d}^{-2}\left(50 \mathrm{~cm}^{2} \mathrm{~s}^{-2}\right)$ and the autocorrelation function to be 0.9 after 6 hours. This produces an estimated error variance of $\sigma_{\mathrm{N}}^{2} \times(1-\mu)=37 \mathrm{~km}^{2} \mathrm{~d}^{-2} \times$ $(1-0.9)=3.7 \mathrm{~km}^{2} \mathrm{~d}^{-2}$ or a velocity error of $\pm 1.9 \mathrm{~km} \mathrm{~d}^{-1}$. Combining these error estimates produces an overall error of $4.6 \mathrm{~km} \mathrm{~d}^{-1}$. Comparison with buoy data in the results section will show that actual errors are lower than this estimate, but with a slight bias towards overestimation. (Error in buoy locations is $\pm 0.3 \mathrm{~km}$, which is negligible).

In addition to these errors, there are errors introduced by the validation procedure resulting from (a) interpolating image estimates of ice displacement to buoy locations and (b) differences in location of the buoy within the start location of a gridcell.

\section{RESULTS}

Table 2 shows the run number, the reference and the matched image dates along with error statistics comparing the vector displacement of the buoy (B) and the vector displacement estimated between image pairs $(\mathbf{T})$. The average bias $(|\mathbf{T}|-|\mathbf{B}|)$ for all the data was 0.28 pixels $(3.5 \mathrm{~km})$, which is $14 \%$ of the average buoy displacement. The average vector error magnitude was 0.96 pixels $(12 \mathrm{~km})$ and the average absolute angle error was $24.3^{\circ}$. Since the average separation between images is 3.6 days for the 25 runs, these pixel errors correspond to a speed bias of $1 \mathrm{~km} \mathrm{~d}^{-1}\left(1.16 \mathrm{~cm} \mathrm{~s}^{-1}\right)$ and vector magnitude error in velocity of $3.5 \mathrm{~km} \mathrm{~d}^{-1}\left(4.0 \mathrm{~cm} \mathrm{~s}^{-1}\right)$. Figure 2

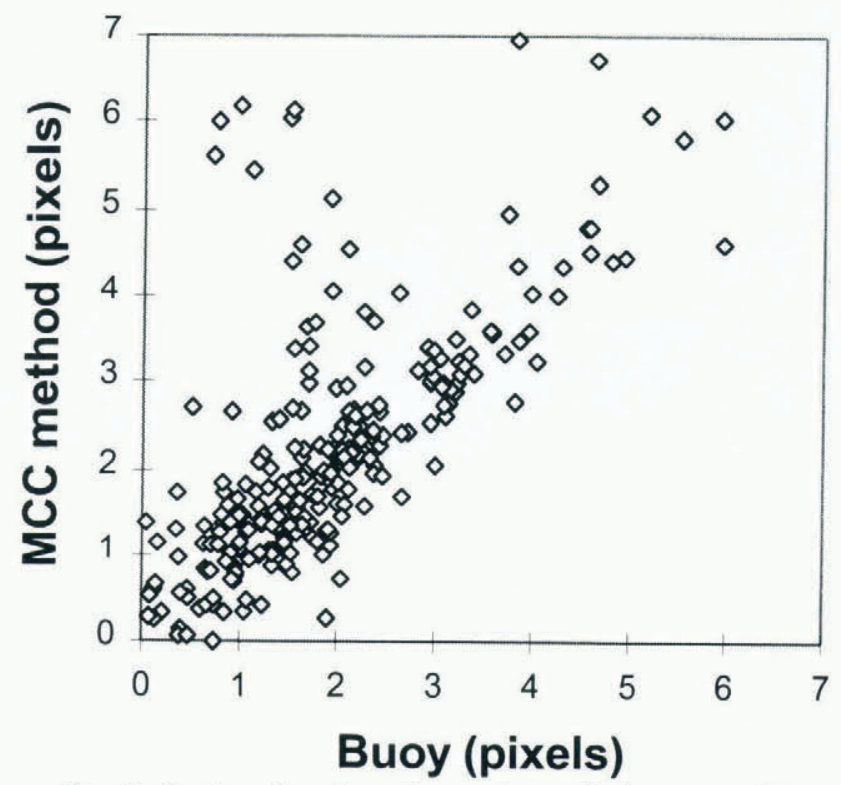

Fig. 2. Scatter plot of tracker vs buoy displacement. 391 comparisons were made. 


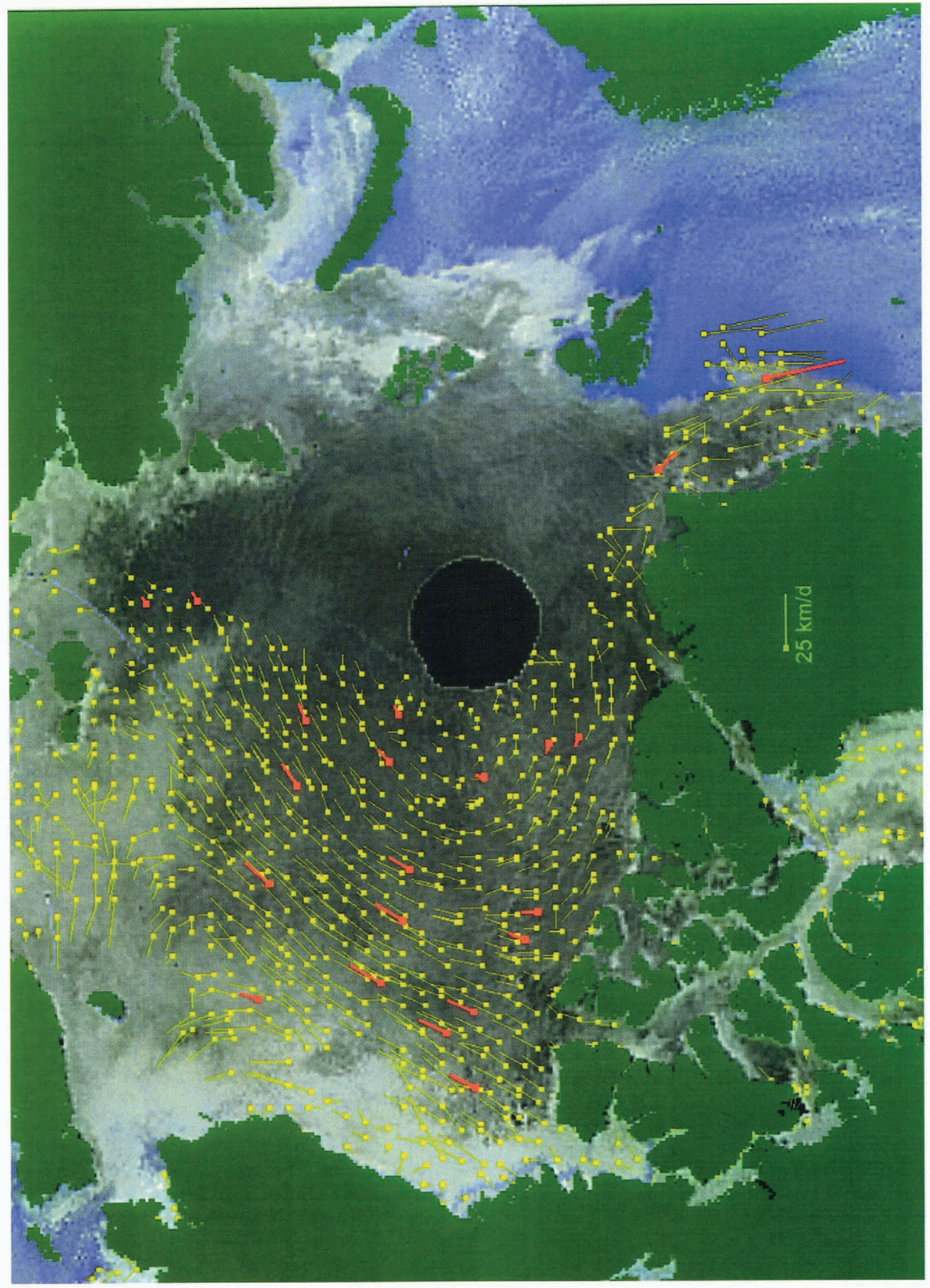

is a scatter plot of the estimated displacement vs buoy displacements for all 391 comparisons. The correlation coefficient is 0.75 and the $x$ axis intercept is 0.53 of a pixel.

The tendency for the image-matching technique to overestimate by $14 \%$ when compared to the buoys is likely to be due to the increased probability of incorrect matches occurring at larger, rather than smaller, displacements than those recorded by the buoys. This is because the number of pixels equal to or less than the actual displacement for a given observation is considerably less than the number of pixels greater than the displacement. Therefore the probability of an incorrect match occurring at larger displacements is higher. This type of error is difficult to correct, but the best method has more stringent criteria for consistency. The distribution of angle errors (not shown) is broad with the most extreme angle errors occurring for weak motions when 
large pixel size leads to coarse angular resolution for small displacements. For example, the angular measurement accuracy for a 1 pixel displacement is $45^{\circ}$ compared to a $15^{\circ}$ accuracy with a 3 pixel displacement. An examination of specific runs showed that the technique had problems in tracking motion in the Marginal Ice Zone (MIZ), especially in the north Greenland Sea, as found by other studies (Holt and others, 1992). This is not surprising since the MIZ is a region of large change and deformation over 3-4 day periods, which separate image pairs in this study.

These error statistics are not as good as results obtained with AVHRR imagery, which is to be expected since SSM/I pixel size is more than ten times larger and geolocation accuracy is not as good. For comparison, Emery and others (1991) obtained a bias of $0.5 \mathrm{~cm} \mathrm{~s}^{-1}$ using $1.1 \mathrm{~km}$ resolution AVHRR imagery, and a standard deviation of $0.9 \mathrm{~cm} \mathrm{~s}^{-1}$ for a 5 day period. Our study was for a longer two month period and results are verified against buoy data over a large part of the Arctic Basin, rather than just the area of Fram Strait.

Overall, ice motions extracted from SSM/I imagery are good in the majority of comparisons with the buoy data, but occasional overestimation of displacement is a problem. It should be kept in mind that there was no pre-screening of the cases to select the best images for testing the technique. Detailed motion over the Arctic Basin for run 03 (image pairs for 7 and 11 December 1993) and run 5 (image pairs for 13 and 17 January1994) are described below.

\section{7-11 December 1993 case study}

During mid December 1993, 85.5 GHz SSM/I animation revealed an almost basin-wide shift in the ice pack between the Canadian Arctic islands and the Siberian side of the Arctic Basin. The main cause was a strong southwesterly gradient over the Beaufort and Chukchi Seas, caused by an intensifying cyclone over Alaska, combined with an anticyclone over the North Pole region. By 8 December, the gradient extended across the western half of the Arctic Ocean and remained there for several days. The basin-wide shift in the pack is evident in the ice displacement vectors estimated from SSM/I image pairs for 7 and 11 December shown in Figure 3. The 4 day ice-motion vector displacements from the buoys are in red, and vector displacements using the MCC technique are in yellow. The small square marks the beginning of the displacement vector. The large circular region centred over the North Pole is the data-void region of the sensor (see data and methodology section). In the background is a false-color SSM/I image for 7 December, obtained by combining the vertical polarization channel in blue with the horizontal channel in red and green. This produced a false-color image dominated by blue over open ocean, and various shades of grey over ice-covered parts of the image. Lighter shades of grey indicate younger first-year ice.

The shift in the ice pack covers almost the entire western half of the Arctic Basin. Motion vectors over the eastern half of the Arctic Basin are not present because the matched SSM/I image for 11 December had missing orbital data. The average displacement in the scene is 3.46 pixels (Table 2 , run 03 ). The average buoy displacement in pixels is 3.48 which, over the 4 day period, corresponds to an average ice motion of $10.8 \mathrm{~km} \mathrm{~d}^{-1}\left(12.5 \mathrm{~cm} \mathrm{~s}^{-1}\right)$ and is the largest motion measured by the buoys during the two month period.
This shift in the ice pack towards the Siberian side of the Arctic exposed a large area of open ocean off Banks and Prince Patrick Islands as wind stresses forced the ice pack offshore. The AVHRR infrared image of the area for 12 December (Fig. 4) shows a very wide lead down the west sides of Banks and Prince Patrick Islands, and in McClure Strait caused by the motion of the pack offshore. These areas refroze rapidly, but remained visible in the SSM/I imagery as young first-year ice (high brightness temperatures) for several months and predisposed the region to rapid melting during the spring breakup.

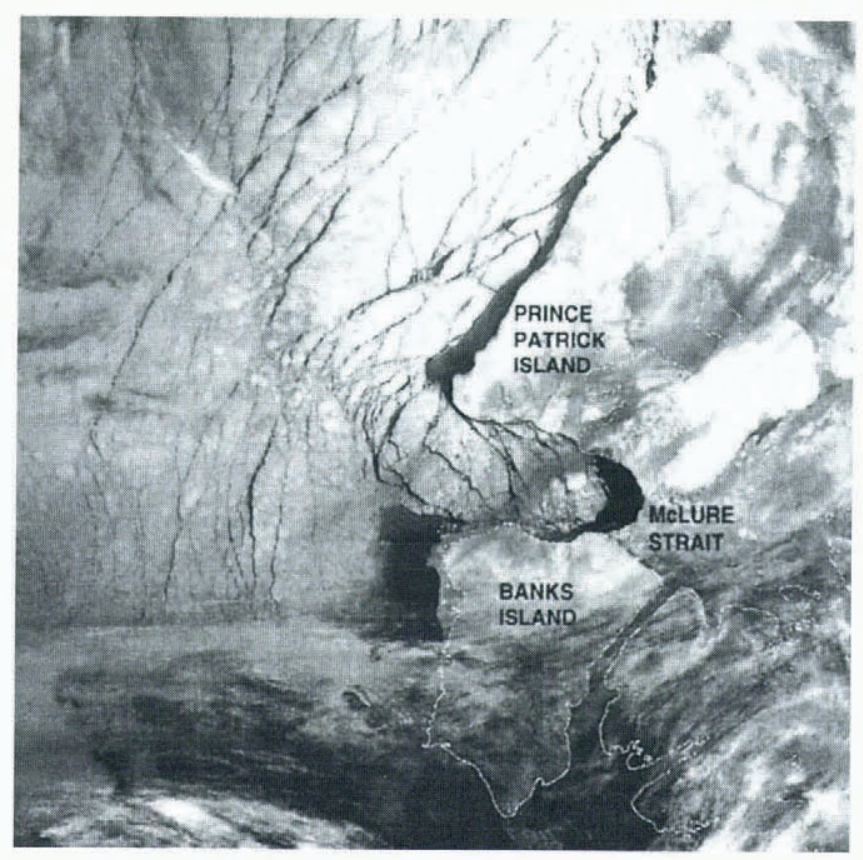

Fig. 4. AVHRR infrared image of 12 December 1993.

\section{3-17 January 1994 case study}

During mid January 1994, SSM/I animation indicated that ice motion in the Beaufort Gyre was very strong. Figure 5 shows ice-displacement vectors estimated from SSM/I for the 4 day period 13-17 January 1994 (run 5). The background image is an SSM/I false-color image for 13 January. The strong anticyclonic circulation of the Beaufort Gyre is apparent as well as large ice motion in Fram Strait. The surface map for 15 January 1994, 1200 h GMT (not shown) indicates a very intense anticyclone circulation over the Canada Basin/Beaufort Sea area and a pressure gradient over the north Greenland Sea. The average displacement from the buoys is 2.10 pixels (Table 2), which corresponds to an average motion of $6.5 \mathrm{~km} \mathrm{~d}^{-1}$. The average motion using image matching is 2.12 pixels at the buoy locations.

Both these cases indicate that the 4 day motion vectors are consistent with atmospheric pressure patterns and compare well with Arctic buoy motions. The SSM/I data show considerably more detail in the motion than is possible from sparse buoy coverage over the Arctic Basin.

\section{CONGLUSIONS}

This paper demonstrates that daily average $85.5 \mathrm{GHz} \mathrm{SSM} / \mathrm{I}$ imagery provides important information on the dynamic behavior of sea ice, especially sea-ice motion and the identi- 


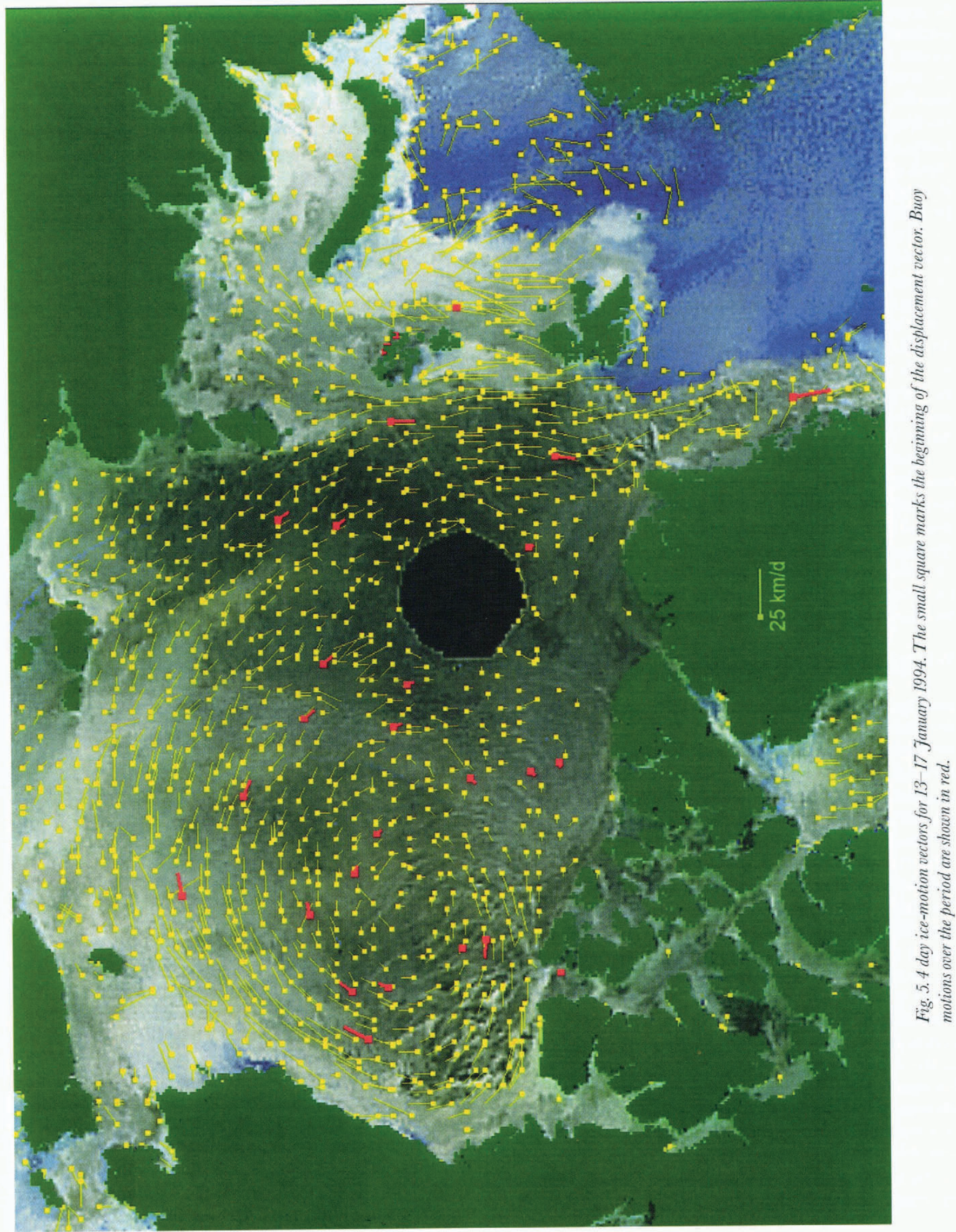

fication of extreme ice-motion events. Although surface ice information is coarse and noisy, MCC methods of detecting motion between pairs of images appear to be successful in detecting ice-motion information. As pointed out by Ninnis and others (1986), MCC is the optimal method for detecting translational motion between noisy images, and this is perhaps the main reason for its success. The daily SSM/I imagery average out random errors in geolocation and timing over the Arctic Basin, which would have to be accounted for in individual swath data. Preliminary results (not discussed in this paper) suggest that using individual swath data with radiometric correction and better geolocation does not significantly improve the comparison with Arctic buoy data. Attenuation due to atmospheric liquid water restricts use of the $85.5 \mathrm{GHz}$ channels to late fall, winter and early spring. 
Comparison statistics were good. However the MCC technique tends to produce a $14 \%$ bias in the estimated motions compared to buoy drift. This $14 \%$ overestimate is likely to be due to increased probability of incorrect matches occurring at larger rather than smaller displacements than those recorded by the buoys. Improved consistency-checking procedures may be able to correct this bias. The technique worked best during periods of strong ice motion within the Arctic Basin but had difficulty in estimating motions in the MIZ, especially in the north Greenland Sea where ice deforms much more rapidly. This is consistent with other studies.

Ice-motion detection using $\mathrm{SSM} / \mathrm{I} 85.5 \mathrm{GHz}$ imagery compliments other types of imagery, such as SAR and AVHRR, in that it can provide large aggregate-scale icemotion information over time periods of months to years. Except for the summer months, it should be possible to produce a large-scale ice-motion dataset over the Arctic Basin every 4 days from mid 1987 to the present, using the 85.5 GHz SSM/I data. These data would provide much more spatial detail than is currently available from buoy data, and would be useful in sea-ice budget studies of the Arctic Basin and in sea-ice model validation. The combination of 85.5 with lower frequency SSM/I data to estimate geophysical properties of sea ice should also be pursued.

\section{ACKNOWLEDGEMENTS}

The authors would like to thank the National Snow and Ice Data Center for providing the processed SSM/I data on CD-ROM and the Polar Science Center, Seattle, Washington for providing the Arctic Buoy data for this study. This work is supported in part by the Canadian Panel on Energy Research and Development.

\section{REFERENCES}

Aagaard, K. and E. C. Carmack. 1989. The role of sea ice and other fresh water in the Arctic circulation. 7. Geophys. Res., 94 (C10), 14,485-14,498.

Emery, W. J., C. W. Fowler, J. Hawkins and R. H. Preller. 1991. Fram Strait satellite image-derived ice motions. J. Geophys. Res., 96 C3), 4751-4768. (Correction: f. Geophys. Res., 96 ( .5), 1991, 8917 -8920.)

Fily, M. and D. A. Rothrock. 1987. Sea ice tracking by nested correlations. IEEE Trans. Geosci. Remole Sensing, GE-24 6), 570-580.

Hirose, T., T. D. Heacock, F. Lee and M. J. Manore. 1991. Advances in sea ice tracking systems. In Franklin, S. E., M. D. Thompson and F. J. Ahern, eds. 14th Canadian Symposium on Remote Sensing, 6-10 May 1991, Calgary, Alta. Proceedings. Ottawa, Ont., Canadian Remote Sensing Societv, 292-295.

Holt, B., D. A. Rothrock and R. Kwok. 1992. Determination of sea ice motion from satellite images. In Carsey, F. D. and 7 others, eds. Microwave remole sensing of sea ice. Washington, DC, American Geophysical Union, 343-354. Geophysical Monograph Series 68.

National Snow and Ice Data Center (NSIDC). 1994. DMSPF-11SSM/I, polar regions. Boulder, CO, University of Colorado. Cooperative Institute for Research in Environmental Sciences. National Snow and Ice Data Center.

National Snow and Ice Data Center (NSIDC). 1996. DMSPSSM/I brightness temperatures and sea ice concentration grids for polar regions. Boulder, CO, University of Colorado. Cooperative Institute for Research in Environmental Sciences. National Snow and Ice Data Center.

Ninnis, R. M., W. J. Emery and M. J. Collins. 1986. Automated extraction of pack ice motion from advanced very high resolution radiometer imagery. 7. Geophys. Res., 91 C9), 10,725-10,734.

Steffen, K. and 6 others. 1992. The estimation of geophysical parameters using passive microwave algorithm. In Carsey, F. D. and 7 others, eds. Microwave remote sensing of sea ice. Washington, DC, American Geophysical Union, 201-231. Geophysical Monograph Series 68.

Thorndike, A. S. 1986. Kinematics of sea ice. In Untersteiner, N., ed. Geophysics of sea ice. London, etc., Plenum Press, 489-549. (NATO ASI Series B: Physics 146.

Thorndike, A. S. and R. Colony. 1980. Arctic Ocean buoy program. Seattle, WA, University of Washington. Polar Science Center. (Data Report.) 